\title{
Comunicación

\section{Books in the digital age. The transformation of Academic and Higher Education Publishing in Britain and the United States}

RAÚl FUENTES NAVARRO*

Profesor de Sociología en Cambridge, John B. Thompson es un autor bien conocido y reconocido en los ámbitos académicos iberoamericanos gracias a las traducciones al español y al portugués de tres de sus libros: Ideology and modern culture (1990), The media and modernity: a social theory of the media (1995) y The political
Thompson, John B.

Books in the digital age. The transformation of Academic and Higher Education Publishing in Britain and the United States.

Cambridge: Polity Press, 2005, 468 páginas.

scandal: power and visibility in the media age (2000). No obstante que las traducciones de estas obras - especialmente las realizadas en España- dejan mucho que desear, los aportes del sociólogo Thompson se han incorporado decisivamente al acervo bibliográfico fundamental para el estudio de los medios de difusión en el contexto de las sociedades contemporáneas. Su propuesta de una «teoría interaccional» basada en buena medida en la teoría de la estructuración de Giddens, pero complementada con relecturas muy acuciosas de Habermas, Ricoeur, Goffman, Bourdieu, Geertz y hasta MacLuhan, así como con los hallazgos empíricos y metodológicos de una gama muy amplia de investigadores «de la comunicación», ha convertido a Thompson en un autor de referencia indispensable.

* Universidad de Guadalajara.

Correo electrónico: raul@iteso.mx 
A fines de 2005 se publicó el libro que remata cinco años de investigación de Thompson sobre una de las industrias culturales contemporáneas menos estudiadas, y sin embargo, protagonista de la mayor importancia para la academia: la industria editorial, y más específicamente, las ramas especializadas en la publicación de libros académicos y de textos universitarios. La pregunta central es por la trasformación de esta industria en el contexto de la revolución digital y el método primordial, la entrevista con los agentes de estas industrias. Para ello Thompson construye su objeto a partir del modelo de los campos de Bourdieu. Puede decirse que la obra es un ejemplo de rigor y pertinencia en el ejercicio de la investigación empírica, una demostración de que los aportes teóricos y la práctica de la investigación no tienen por qué concebirse tan separados y distintos como a veces se hace.

La obra consta de cuatro partes y 15 capítulos, que en conjunto abarcan más de 450 páginas. En el mejor estilo académico inglés, hay pocas palabras, párrafos o partes que no justifiquen su necesidad en el flujo de un discurso denso, pero muy sistemático y preciso. Desde el prefacio, el lector sabe con claridad cual es el planteamiento del trabajo, que enfrenta la ola de especulaciones sobre el futuro del libro en la «era digital» desatada en los años noventa. Para hacerlo, Thompson distingue los campos de las publicaciones académicas (monografías) y de los libros de texto para la educación superior, entre sí y del resto de las ramas especializadas de la industria editorial, ya que sus dinámicas como campos específicos tienen condiciones y características particulares, y se restringe a los libros publicados en inglés, tanto en Gran Bretaña como en Estados Unidos. Pero la contextualización de estos sectores industriales es amplia:

En tanto que comprender el mundo de la publicación sólo es posible mediante la comprensión de cómo trabajan los campos editoriales específicos y de cómo se relacionan con otros campos sociales, al mismo tiempo podemos ver que hay ciertos desarrollos más amplios que han afectado el mundo editorial como un todo en los años recientes $-\mathrm{y}$, por supuesto, algunos de esos desarrollos han afectado también a otros sectores de la industria. Los modos particulares en que esos desarrollos más amplios se han manifestado en el mundo de la publicación varían de campo a campo. Algunos de esos 
desarrollos son más significativos en algunos campos que en otros, y en cada uno de los campos las maneras específicas en que se manifiestan esos desarrollos están siempre conformadas por las propiedades distintivas del campo (2005:8).

Thompson apunta cuatro como los principales de esos «desarrollos» y los utiliza como ejes analíticos en toda la obra:

1. La creciente concentración (o «conglomeratización») de los recursos, que ha afectado relativamente poco al campo de la publicación académica, a diferencia de otros campos.

2. La cambiante estructura de los mercados y de los canales hacia ellos, con el surgimiento de grandes intermediarios en las cadenas de distribución (como Barnes \& Noble), incluyendo a los puramente digitales (como Amazon.com).

3. La globalización de los mercados y de las firmas editoras, que hace que los grandes conglomerados, pero también las editoriales pequeñas y especializadas, operen sobre una base trasnacional.

4. El impacto de las nuevas tecnologías. La revolución digital ha trasformado la administración de la industria, al igual que en todas las demás, pero también la producción de los bienes: los libros impresos. Sin embargo, como estos productos en cuanto contenidos, son también totalmente digitalizables, la industria editorial enfrenta problemas parecidos a los de otras industrias culturales, como la de la música, que parecen amenazar la necesidad misma de la existencia de los bienes en cuanto a su soporte físico tradicional, el papel (ibid.: 8-10).

Desde este planteamiento, es obviamente ingenua la discusión sobre la sustitución directa de los libros impresos por los libros digitales y poco relevante la discusión sobre el cambio de los patrones, hábitos y competencias de lectura (o consumo) de textos escritos crecientemente soportados digitalmente. Menos justificada aún queda la alarma sobre las consecuencias culturales de la «desaparición» del libro, al menos en los campos especializados que estudia Thompson. Por lo pronto, al menos, no hay evidencias de que formas cada vez más sofisticadas de «e-books» vayan a hacer desaparecer a los libros (académicos) impre- 
sos ni que esto suponga la trasformación radical de los formatos o los contenidos de los textos que circulan por esos medios.

Sin embargo, hay crisis (trasformaciones profundas) en las industrias editoriales y cambios, sin duda notables, en los campos específicos. Algunos de los factores de esos cambios provienen claramente de las innovaciones tecnológicas, sobre todo en los procesos de producción, que están casi totalmente digitalizados, y en los de distribución. El tamaño de los tirajes, por ejemplo, no es ya un límite para la recuperación de las inversiones, pues tiende a establecerse el sistema de impresión sobre demanda, lo cual evita el almacenamiento, gracias a la estructura de costos de la impresión digital, muy distinta de la analógica (offset). Pero como la tecnología, con todos sus avances, no es aislable de otros factores, o «desarrollos» como los llama Thompson, tanto en el entorno como al interior de las empresas, es necesario considerar las dinámicas completas (y complejas) de los campos específicos.

El análisis detallado y sistemático que Thompson realiza de una gran cantidad de tipos de datos, especialmente de la información proveniente de las entrevistas con los actores de esta industria, permite interpretar -y en muchos casos reinterpretar- las articulaciones que constituyen los campos, más allá de sus estructuras propiamente económicas, sin duda importantes. Por ejemplo, hay cambios fuertes en las tendencias y criterios de adquisición de libros académicos por parte de las bibliotecas universitarias (que en el mundo anglosajón son los «clientes» fundamentales de las editoriales), relacionados con los precios en el campo adyacente de las publicaciones periódicas especializadas (journals), y también hay estrategias nuevas de mercadeo, muy exitosas, de los libros de texto universitarios o de los «paquetes» de textos de lectura para cursos superiores.

En suma, hay diferencias en la trasformación por la que atraviesan los campos de la publicación de monografías académicas y de libros de texto universitario, que parecieran a primera vista una sola cosa. Pero de que hay trasformaciones radicales en proceso, no queda duda. Lo que la investigación de Thompson muestra es que el sentido de esas trasformaciones, y el lugar que ocupa la tecnología digital entre los factores que las impulsan, no es algo predeterminado o simple de conocer. De hecho, nadie, dentro o fuera de la industria editorial, sabe «qué va 
a pasar» en los próximos años. Y esa conclusión es muy relevante para la exploración de las industrias culturales y del mundo contemporáneo. Con la precisión y contundencia típicas del autor, cabe reconocer con él que:

Si queremos comprender cómo está afectando (y es muy probable que lo siga haciendo) la revolución digital a las industrias creativas, tenemos que situar esos desarrollos en el contexto de un análisis mucho más profundo de esas industrias como tales, de cómo están organizadas, de cómo sirven a sus mercados y cómo están cambiando, tanto ellas como éstos últimos. Las tecnologías no transforman las prácticas sociales en sí y por sí mismas, como deus ex machina; en cambio, las tecnologías son adoptadas y usadas (o no, en su caso) por agentes en contextos específicos, dependiendo de si son vistas por ellos como útiles para resolver problemas específicos o capaces de generar algo valioso para ellos. El espacio de las décadas más recientes está tan lleno de suficientes ejemplos de especulación equivocada sobre el impacto de la revolución digital, que cualquier persona razonablemente sensata debe abstenerse de hacer más contribuciones a ese género (ibid.: 438).

Sin duda las industrias creativas - mejor término, quizá, que «industrias culturales»- del mundo de habla hispana, tienen condiciones muy diferentes de las del mundo anglosajón, pero también indudablemente existen y se trasforman en función de los mismos «desarrollos» o factores centrales de la «globalización». Habría que profundizar en su investigación sistemática y por ello en su comprensión, que por más que se han extendido y agudizado, no alcanzan a contrarrestar o impedir el imperio entre nosotros o de la «especulación equivocada» o de la indiferencia académica. 